Check for updates

Cite this: RSC Adv., 2018, 8, 31646

\section{Ameliorative effects and possible molecular mechanisms of action of fibrauretine from Fibraurea recisa Pierre on D-galactose/ $\mathrm{AlCl}_{3}-$ mediated Alzheimer's disease}

\author{
Zhiheng Xing, ${ }^{a}$ Zhongmei He, (D) *ab Shuning Wang, ${ }^{a}$ Yu Yan, ${ }^{a}$ Hongyan Zhu, ${ }^{\text {ab }}$ \\ Yugang Gao, ${ }^{\text {ab }}$ Yan Zhao ab and Lianxue Zhang*ab
}

Fibrauretine is one of the main active ingredients from the rattan stems of Fibraurea recisa Pierre It exhibits a series of significant pharmacological effects. The present study aimed to evaluate the potential anti Alzheimer's disease (AD) effects of fibrauretine on a D-galactose/ $/ \mathrm{AlCl}_{3}$-induced mouse model, and the underlying mechanisms of action were further investigated for the first time. Our results showed that pretreatment with fibrauretine significantly improved the ability of spatial shortterm working memory in the model mice during the $\mathrm{Y}$-maze test, as well as the abilities of spatial learning and memory during the Morris water maze. The levels of brain tissue amyloid (A $\beta$ ), P-Tau, Tau and acetylcholinesterase (AchE) were evidently increased in D-galactose/AlCl 3 -intoxicated mice, and these effects were reversed by fibrauretine. In contrast, a significant increase in the levels of the neurotransmitter acetylcholine (Ach) and choline acetyl transferase (ChAT) was observed in the fibrauretine-treated groups compared with the model group. Neuronal oxidative stress, evidenced by increased malondialdehyde (MDA) and nitric oxide (NO) levels and a decline in glutathione (GSH), catalase (CAT) and superoxide dismutase (SOD) activity, was significantly alleviated by fibrauretine pretreatment. The suppression of the neuroinflammatory response by fibrauretine was realized not only by the decrease in the levels of tumour necrosis factor- $\alpha$ (TNF- $\alpha$ ) and interleukin-1 $\beta$ (IL-1 $\beta$ ) in the brain tissues and by the enzyme-linked immunosorbent assay (ELISA) but also by the protein expression levels of nuclear factor $-\kappa B(N F-\kappa B)$, cyclooxygenase-2 (COX-2), and inducible nitric oxide synthase (iNOS), which were measured by immunohistochemistry and western blotting. In addition, the protein expression levels of inflammatory factors interleukin-33 (IL-33) and ST2 in the brain tissues were detected by immunohistochemistry. Furthermore, the effects of western blotting demonstrated that the administration of fibrauretine significantly suppressed the protein expression levels of caspase-3, cleaved caspase-3, and Bax and increased the protein expression levels of $\mathrm{Bcl}-$ 2, and the results of the H\&E and TUNEL assay all suggested the inhibition of apoptosis in the neurons. The results clearly suggest that the underlying molecular mechanisms of action of the fibrauretine-mediated alleviation of $\mathrm{D}$-galactose/ $\mathrm{AlCl}_{3}$-induced Alzheimer's disease may involve antioxidant, anti-inflammatory, and anti-apoptotic effects.
Received 22nd June 2018 Accepted 26th August 2018

DOI: $10.1039 / \mathrm{c} 8 \mathrm{ra05356a}$ rsc.li/rsc-advances hallmarks of $\mathrm{AD}$ include the presence of extracellular $\mathrm{A} \beta$ amyloid plaque (AP) deposition and the intracellular formation of neurofibrillary tangles (NFTs) in the brain, together with synaptic dysfunction characterized neurochemically by a consistent deficit in cholinergic neurotransmission and a significant loss of neuronal cells. ${ }^{3}$ These lesions contain hyperphosphorylated tau and an excess of reactive glia in the AD brain. ${ }^{4,5}$ The characteristics of the ageing model for $\mathrm{D}^{-}$ galactose-induced $\mathrm{AD}$ mice is close to the pathological changes of clinical AD patients. A large amount of aluminium ions may induce AP deposition and formation of NFTs and is a common damage model of the cholinergic system in $\mathrm{AD}$. AD ajilin Agricultural University, Changchun 130118, Jilin, China. E-mail: heather78@ 126.com; Fax: +86431 84533358; Tel: +8643184533358

${ }^{b}$ College of Chinese Medicinal Materials, Changchun 130118, Jilin, China 
model mice may be effectively induced by D-galactose combined with $\mathrm{AlCl}_{3}$ (D-galactose $\left./ \mathrm{AlCl}_{3}\right){ }^{6-8}$

The mechanisms underlying the progression of $\mathrm{AD}$ remain complicated. The continuous generation and abnormal accumulation of $A \beta$ in the brain causes microglial dysfunction by reducing $A \beta$ receptors, increasing the production of inflammatory mediators, ${ }^{9}$ including TNF- $\alpha$, IL-1 $\beta$, NF- $\kappa B$, COX-2 and iNOS. Therefore, chronic neuroinflammation induced by microglia contributes to pathological progression and symptom severity, usually in the late stages of AD. Interleukin-33 (IL-33) is a new member of the IL-1 family, whose specific receptor is ST2. ${ }^{10} \mathrm{IL}-33$ is constitutively expressed in the central nervous system (CNS), may induce inflammatory molecule release from glial cells and plays an important role in the pathogenesis of AD. ${ }^{11}$

Oxidative stress is an imbalance between the oxidation and reduction reactions, resulting in the production of reactive oxygen species (ROS). ${ }^{12}$ Oxidative stress plays a very important role in the etiopathogenesis of $\mathrm{AD}^{.{ }^{13}}$ Free radicals can be produced by microglial activation and generated by $\beta$-amyloid plaques. Additionally, the activation of a series of signalling protein pathways such as inflammatory pathway nuclear factor$\kappa \mathrm{B}(\mathrm{NF}-\kappa \mathrm{B})^{14}$ can be triggered by ROS-mediated oxidative stress. Neuronal apoptosis is believed to lead to $\mathrm{AD}$, and apoptosis also plays a vital role in the pathophysiology of $\mathrm{AD} .{ }^{15,16}$ Apoptosis is a sophisticated biological mechanism involving a wide variety of anti-apoptosis proteins such as Bcl-2 and pro-apoptotic protein such as Bax. ${ }^{17}$ Caspase-3, the effector caspase and final executor of apoptosis, can cleave cytoskeletal and nuclear proteins. ${ }^{18}$

Several studies have focused currently on natural ingredients from traditional herbal medicines to evaluate novel therapeutic drugs for the therapy of AD. Various natural ingredients, including luteolin, tetrahydropalmatine and berberine have been shown ameliorative effects on $\mathrm{AD}$ in vivo experiments. ${ }^{19-21}$

The rattan stems of Fibraurea recisa Pierre is rich in resources and mainly distributed in Yunnan and Guangxi, China, known as natural antibiotics, have traditionally been used in the treatment of gynaecological inflammation and surgical infection. The rattan stems contains a kind of isoquinoline alkaloid, one of the main active ingredients, fibrauretine. More significant pharmacological activities of fibrauretine have been discussed in the previous study, involving antitumour, ${ }^{22,23}$ anti-osteoarthritis, ${ }^{24}$ antiviral, ${ }^{25}$ neuroprotective, ${ }^{26,27}$ antidepressant ${ }^{28}$ effects and lowering blood lipids. ${ }^{29}$

In this paper, fibrauretine was extracted and purified from the rattan stems of Fibraurea recisa Pierre with $60.75 \%$ extraction rate. The anti-AD effects of fibrauretine against D-galactose/ $\mathrm{AlCl}_{3}$-induced $\mathrm{AD}$ surveyed on a mouse model were proposed for the first time by us. The new discovery has been authorized by the State Intellectual Property Office of China (ZL201510253034.6). In addition, the potential molecular mechanisms underlying these anti-AD effects are discussed, involving antioxidant, anti-inflammatory, and anti-apoptotic activity.

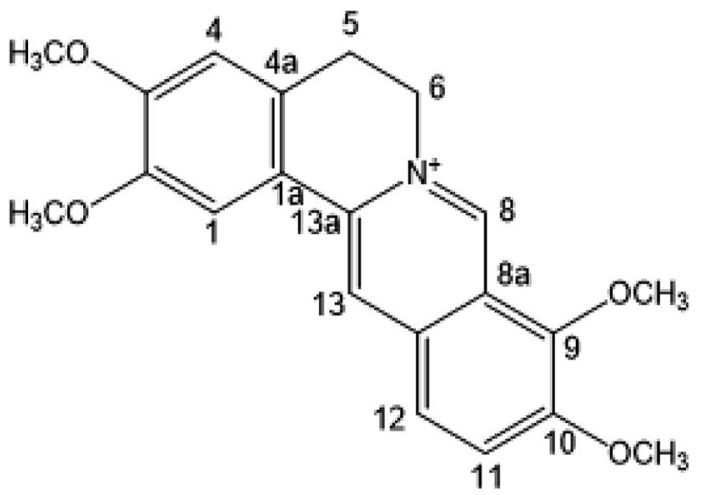

fibrauretine

\section{Materials and methods}

\subsection{Preparation of fibrauretine}

The rattan stems of Fibraurea recisa Pierre were purchased in September 2015, in Kunming of Yunnan Province, China and were identified by Prof. Lianxue Zhang. The voucher specimen was deposited at the laboratory.

The air-dried rattan stems ( $2 \mathrm{~kg}, 60 \mathrm{mesh})$ were extracted two times with $70 \%$ ethanol by reflux extraction, each time for 2 hours. The extracts were filtered, combined and concentrated under reduced pressure to give $228.3 \mathrm{~g}$ of extract. The extracts were then dissolved in water and passed through a pre-treated D101 macroporous resin column $(\Phi 1000 \times 100 \mathrm{~mm})$, washed with 3 column volumes of water, and then eluted with 8 column volumes of $40 \%$ ethanol. The ethanol eluate was collected, the ethanol was recovered, and the eluate was then dried to yield total alkaloids $(50.6 \mathrm{~g})$. Total alkaloids $(10 \mathrm{~g})$ were dissolved in $95 \%$ ethanol, chromatographed on a basic alumina column $(200 \mathrm{~g}, \Phi 880 \times 100 \mathrm{~mm})$ and eluted with $95 \%$ ethanol for elution at atmospheric pressure. The alkaloids were detected by thin layer chromatography (TLC) and separated to give compound A and component I. Component I was subjected to gradient elution with methanol-water $(10: 90-50: 50)$ on an ODS column $(\Phi 420 \times 36 \mathrm{~mm})$ to afford fibrauretine $(24.3 \mathrm{~g})$. The purity of fibrauretine was determined by HPLC (purity $>98 \%$ ), and the structure was identified by ${ }^{1} \mathrm{H}-\mathrm{NMR}$ and ${ }^{13} \mathrm{C}-\mathrm{NMR} .{ }^{30}$

\subsection{Animals and experimental protocol}

ICR mice (male, weighing 18-22 g, SPF grade) were provided by YISI Experimental Animals Co., Ltd. (Certificate no. SCXK-20160003, Jilin, China). Animals were kept under standard laboratory conditions: room temperature at $23 \pm 2{ }^{\circ} \mathrm{C}$, humidity of 60 $\pm 10 \%$. The mice were allowed free access to food and water during the experiments. All experimental procedures were approved by the Institutional Animal Ethical Committee and were authorized by the Animal Care Committee of Jilin Agricultural University (2016-01-Permit number: ECLA-JLAU 2016016), the reference is Guide for the Care and Use of Laboratory Animals (Eighth Edition, the National Academies Press Washington, D.C.) and AVMA Guidelines for the Euthanasia of 
Animals: 2013 Edition (American Veterinary Medical Association).

After acclimation for 3 days, 10 mice were randomly selected as a control group. The remaining 80 mice received intraperitoneal injections with D-galactose at a dose of $120 \mathrm{mg} \mathrm{kg}^{-1}$ and were administered $\mathrm{AlCl}_{3}$ intragastrically at a dose of $20 \mathrm{mg} \mathrm{kg}$ daily for 40 continuous days to induce $\mathrm{AD}$ in mice. The control group mice were injected intraperitoneally and administered intragastrically with the same amount of saline. From the $35^{\text {th }}$ to the $40^{\text {th }}$ day, after $1 \mathrm{~h}$ of being given $\mathrm{D}$-galactose $/ \mathrm{AlCl}_{3}$, the memory behaviour of the mice was trained using the Y-type maze test for five continuous days. The eligible mice were randomly divided into 5 groups $(n=10)$ and were then treated for the second forty days according to methods mentioned above. All mice were administered intragastrically with different drugs from the $41^{\text {st }}$ day for 40 continuous days. According to our previous study of the $\mathrm{LD}_{50}$ of fibrauretine $\left(4.8 \mathrm{~g} \mathrm{~kg}^{-1}\right)$ and the preliminary experiment, the groups for fibrauretine administration were, respectively, given different dosages (80, 160, $320 \mathrm{mg} \mathrm{kg}{ }^{-1}$ ). The positive control group was treated with donepezil hydrochloride $\left(1 \mathrm{mg} \mathrm{kg}^{-1}\right)$. Fibrauretine and donepezil hydrochloride were, respectively, suspended in $0.05 \%$ carboxymethylcellulose sodium (CMC-Na) before being used. The control group mice and the model group mice received intragastrical injections with $0.05 \%$ CMC-Na. The administration operators were blind to the tested materials, and the testers were also blind to the drug treatment.

All mice were weighed every three days. Eighty days later, after $1 \mathrm{~h}$ from the last administration, each group of mice was subjected to the Morris water maze and the Y-maze test and
A

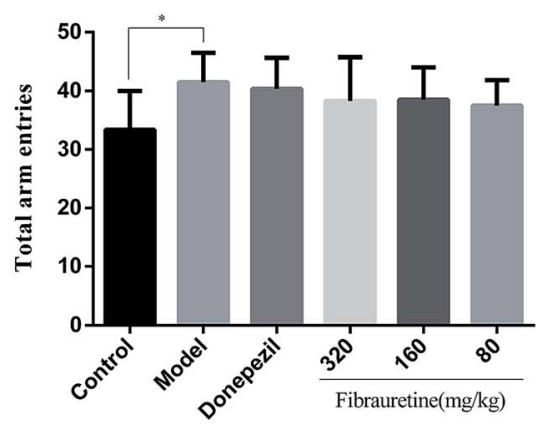

C

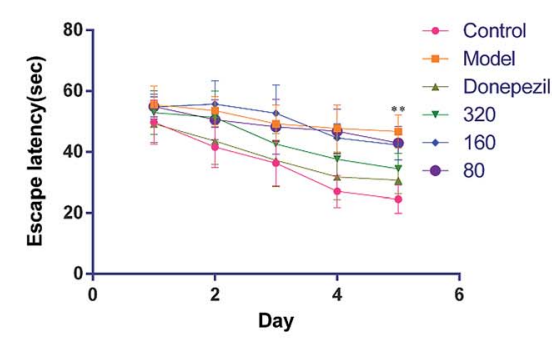

E

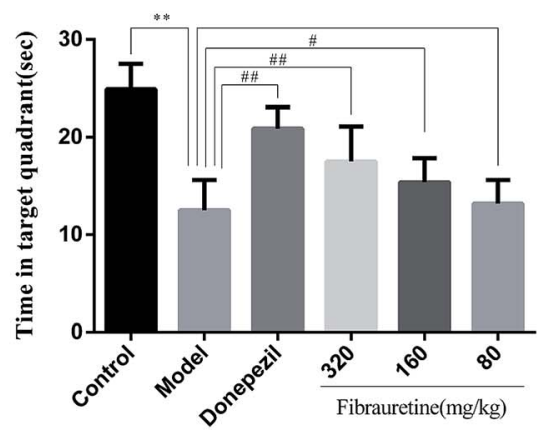

B

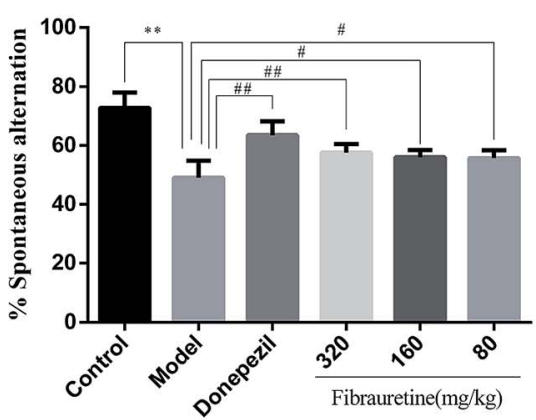

D

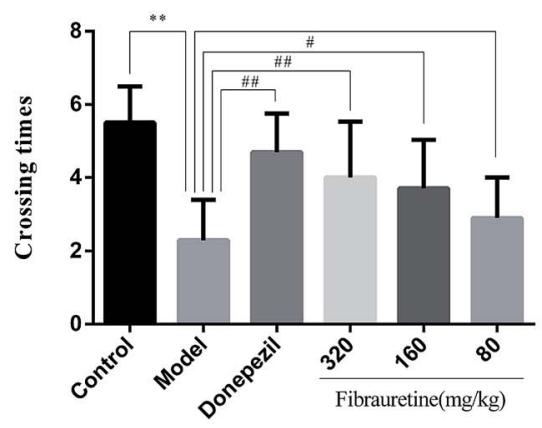

Fig. 1 Effect of fibrauretine and donepezil on total arm entries (A); spontaneous alternation (B); escape latency (C); crossing times (D); time in target quadrant (E) from $\mathrm{D}$-galactose/AICl 3 -induced $\mathrm{AD}$ mice. All data were expressed as the mean $\pm \mathrm{SD}, n=10$. ${ }^{*} p<0.05, * * p<0.01$ vs. control group; ${ }^{\#} p<0.05,{ }^{\# \#} p<0.01$ vs. model group. 
then was sacrificed under general anaesthesia. Blood and sample collection was performed immediately. The brain tissue was promptly frozen in liquid nitrogen and stored at $-80{ }^{\circ} \mathrm{C}$ until analysis, and the brain tissue was fixed in $10 \%$ neutral buffered formalin. Subsequently, serum samples were separated using a refrigerated centrifuge at $3000 \times g$ and stored at $-20{ }^{\circ} \mathrm{C}$ until used for subsequent analysis.

\section{$2.3 \quad$ Y-maze test}

The mice were evaluated for short-term spatial memory by a Ymaze test as previously described. ${ }^{31}$ The Y-maze consisted of three identical arms $(60 \mathrm{~cm}$ in length, $10 \mathrm{~cm}$ in width, and $15 \mathrm{~cm}$ in height), 120 degrees to each other. The mice were individually placed at the end of either arm and allowed to move freely through the maze within 5 minutes. Mice actively explore the maze, enter each arm in order, and remember which arm they have already entered. Spontaneous alternation is defined as the continuous entry of three arms (e.g., $1 / 2 / 3$ or $1 / 3 / 2)$, and the spontaneous alternation rate is the ratio of the actual number of alternations to the number of possible alternations (the total number of arms minus 2) multiplied by $100 \%$.

\subsection{Morris water maze}

The spatial learning and memory of mice was tested by a water maze as described in. ${ }^{32}$ The Morris water maze consisted of a $100 \mathrm{~cm}$ diameter pool that was filled with water $\left(22^{\circ} \mathrm{C}\right)$. The pool was divided into four equal quadrants, and there were visual cues in each quadrant. Mice were accepted to the hidden platform test from day 1 to day 4 , with a probe trial on the fifth day. In the hidden platform test, the platform was placed $1 \mathrm{~cm}$ underwater, and each time, the mice were randomly placed in different starting positions; they were given 60 seconds to climb the hidden platform. If no platform could be found within 60 seconds, mice were guided to the platform and allowed to remain on the platform for 10 seconds. In the probe trial, the platform was removed, and mice were put into the pool to swim
A

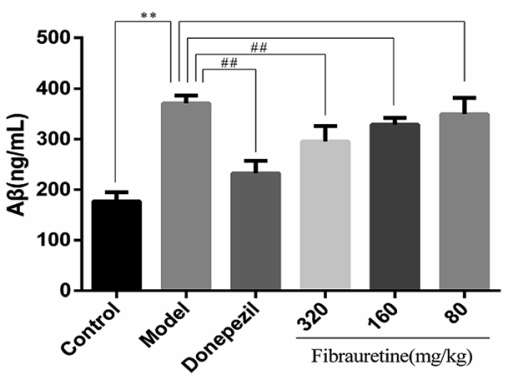

C

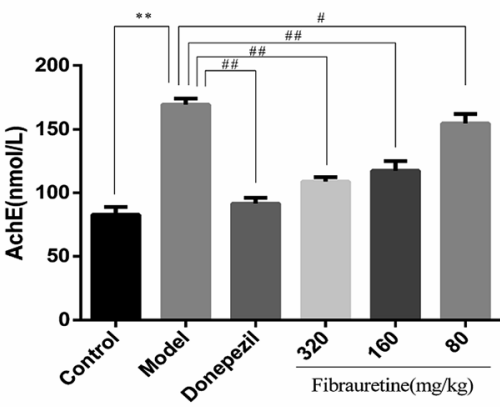

$\mathbf{E}$

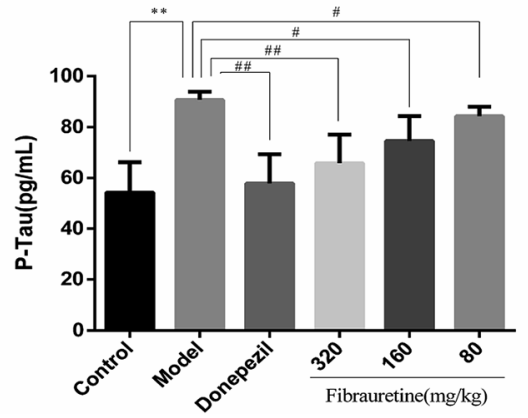

B

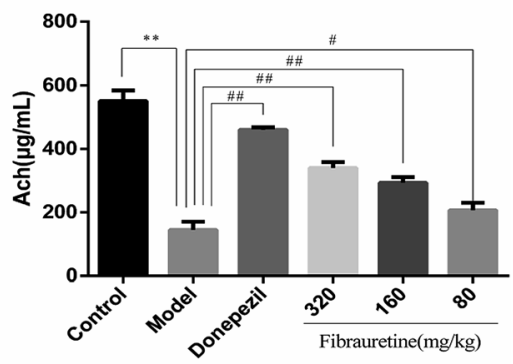

D

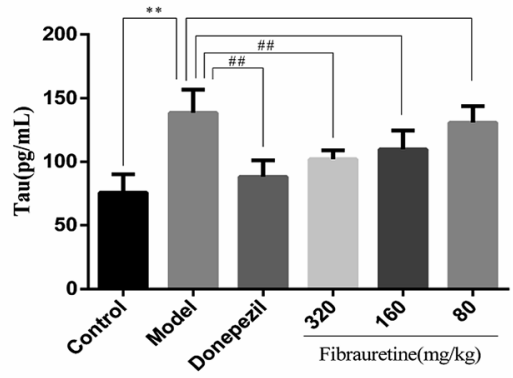

$\mathbf{F}$

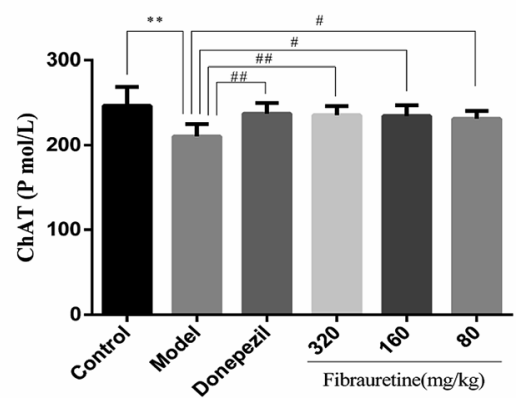

Fig. 2 Effects of fibrauretine and donepezil on the level of brain $A \beta(A)$; the level of brain Ach (B); the level of brain AchE (C); the level of brain Tau (D); the level of brain P-Tau (E); and the level of brain ChAT (F) in D-galactose/AICl 3 -induced AD. All data are expressed as the mean $\pm S D, n=10$. ${ }^{*} p<0.05,{ }^{* *} p<0.01$ vs. control group; ${ }^{\#} p<0.05,{ }^{\# \#} p<0.01$ vs. model group. 
for 60 seconds. The memory consolidation 24 hours after the last hidden-platform trial was assessed. The time the mouse spent in the target quadrant and the number of crossings were detected.

\subsection{Assessment of biochemical parameters}

The brain tissue levels of A $\beta$, AchE, Ach, Tau, P-Tau, ChAT, GSH, TNF- $\alpha$ and IL-1 $\beta$, as well as the serum levels of MDA, NO, CAT and SOD, were measured by ELISA. Brain tissue from each group was homogenized on ice, serum samples were segregated using a refrigerated centrifuge at $3000 \times g$, then all samples were tested immediately by the ELISA kit (all purchased from R\&D systems) according to the manufacturer's instructions.

\subsection{H\&E staining assay}

Histopathological examination was performed as previously described. ${ }^{33}$ Briefly, brain tissues were fixed in $4 \%$ formaldehyde solution. After deparaffinization with xylene, the tissues were dehydrated with different concentrations of ethanol and cut into $5 \mu \mathrm{m}$-thick slices. Then, all slices were stained with H\&E staining solution and PAS reagents for histopathological analysis. The results were detected by optical microscope (Olympus, BX51T-PHD-J11, Japan).

\subsection{TUNEL staining assay}

The TUNEL staining assay was conducted to measure the extent of apoptosis in the brain after $\mathrm{D}$-galactose $/ \mathrm{AlCl}_{3}$ exposure. TUNEL evaluation was typically carried out as follows. ${ }^{34}$ First, the brain sections ( $5 \mu \mathrm{m}$-thick) were incubated with $100 \mu \mathrm{L}$ of 20 $\mu \mathrm{g} \mathrm{mL}{ }^{-1}$ proteinase $\mathrm{K}$ solution at room temperature for $15 \mathrm{~min}$. Next, the sections were incubated with $100 \mu \mathrm{L}$ of $3 \% \mathrm{H}_{2} \mathrm{O}_{2}$ for 10 min and washed with PBS two times. Then, the TUNEL reaction mixed solution was added to the sections, and the sections were put into a humid chamber at $37^{\circ} \mathrm{C}$ for $1 \mathrm{~h}$.

\section{A}

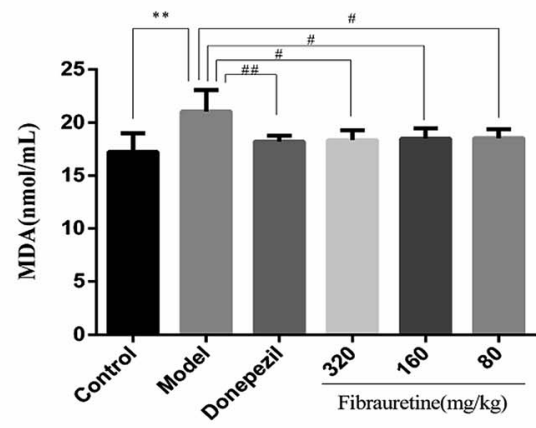

C

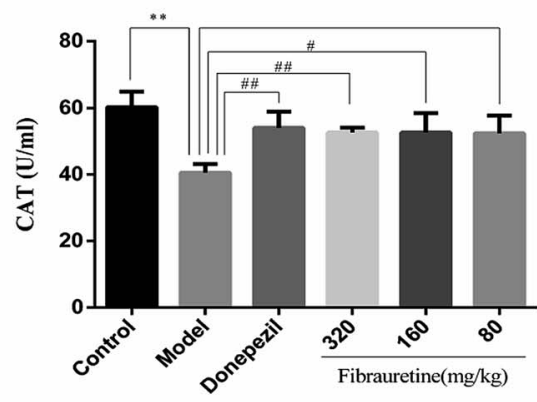

E

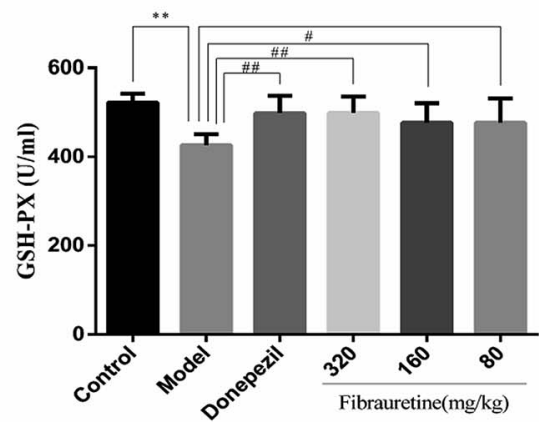

B

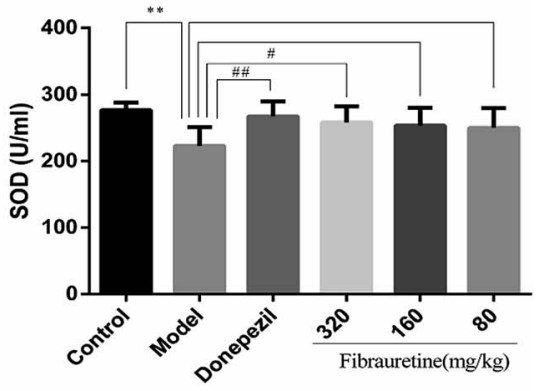

D

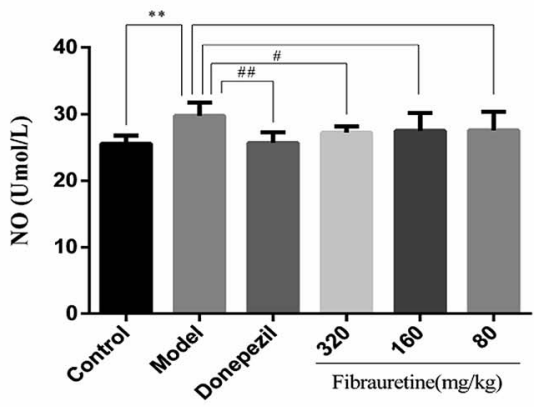

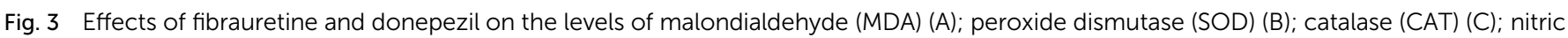

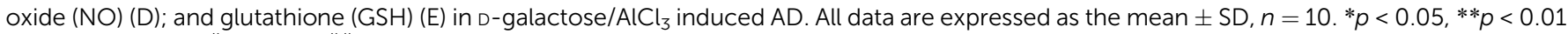
vs. control group; ${ }^{\#} p<0.05,{ }^{\# \#} p<0.01$ vs. model group. 
Subsequently, the sections were incubated with $50 \mu \mathrm{L}$ POD for 30 min after washing three times with PBS. Finally, the slices were counterstained with haematoxylin. TUNEL-positive cells were visualized with an Olympus microscope (Olympus BX51, Japan).

\subsection{Immunohistochemistry (IHC) analysis}

IHC analysis was performed as mentioned earlier. ${ }^{35}$ First, $5 \mu \mathrm{m}$ thick brain sections were de-paraffinized and hydrated with aqueous alcohol solution. The sections were blocked with endogenous peroxidases for $10 \mathrm{~min}$ at room temperature, followed by rinsing 3 times in PBS (0.01 M, pH 7.4) for $3 \mathrm{~min}$. Then, the sections were put into citrate buffer solution $(0.01 \mathrm{M}, \mathrm{pH}$ 6.0) in a microwave oven (medium high temperature) for $15 \mathrm{~min}$. When the temperature came to $25^{\circ} \mathrm{C}$, the sections were washed three times with PBS. Next, the slides were incubated with $1 \%$ BSA for $1 \mathrm{~h}$ and incubated in a humidified chamber at $4{ }^{\circ} \mathrm{C}$ overnight with initial antibodies involving NF- $\kappa \mathrm{B}(1: 200)$, Bax (1:200), Bcl-2 (1:200), iNOS (1:200), COX-2 (1:200), IL-33 (1:200) and ST2 (1:200), followed by HRP-conjugated secondary antibody for $30 \mathrm{~min}$. The sections were incubated with labelled streptavidin-biotin for $30 \mathrm{~min}$. Finally, the sections were followed by DAB staining and counterstained with haematoxylin. The sections were dehydrated with alcohol and cleared with xylene. The immunostaining results were analysed by light microscopy (Olympus BX51, Japan).

\subsection{Western blotting analysis}

Western blotting analysis was carried out as mentioned previously. ${ }^{36}$ First, brain tissue samples from each group were homogenized with lysis buffer plus $1 \mathrm{mM}$ PMSF and protease inhibitor. Protein concentrations were determined using a BCA protein assay kit. The proteins $(20 \mu \mathrm{g}$ per lane) from each sample were separated with $12 \%$ SDS-PAGE and transferred to a polyvinylidene fluoride (PVDF) membrane. Then, the membrane was blocked with $5 \%$ fat-free milk in tris-buffered saline (TBS) containing $0.1 \%$ Tween-20 for $2 \mathrm{~h}$ in a room temperature environment, after being incubated with primary antibodies at $4{ }^{\circ} \mathrm{C}$ overnight. Caspase-3, cleaved caspase-3, Bax, Bcl-2, NF-кB, COX-2 and iNOS were probed with the corresponding primary antibodies (1:1000), followed by incubation with HRP-conjugated anti-mouse anti-body or HRP-anti-rabbit antibody. Finally, the blots were inspected by the Emitter Coupled Logic (ECL) substrate with a KODAK Image Station 4000 MM (Carestream Health, Inc., New Haven, CT, USA).

\subsection{Statistical analysis}

All data were expressed as the means \pm standard deviation (SD) of ten animals in each group and were characterized by a oneway analysis of variance (ANOVA) using SPSS17.0 (SPSS, Chicago, IL, USA). Values of $p<0.05$ were considered significant, and $p<0.01$ was considered highly statistically significant.

\section{Results}

\subsection{Effects of fibrauretine on the abilities of learning and memory in $\mathrm{D}$-galactose/ $\mathrm{AlCl}_{3}$-treated mice}

The behaviour effect of fibrauretine on $\mathrm{D}^{-g a l a c t o s e} / \mathrm{AlCl}_{3}$ induced AD mice was assessed using a Y-maze test and a Morris water maze test. The results are shown in Fig. 1.

The results from the Y-maze test showed that a single treatment with D-galactose $/ \mathrm{AlCl}_{3}$ raised the total arm entries in the model group compared with the control group $(p<0.05)$, and there was no significant difference between the model group and the fibrauretine-administered group ( $p>0.05$ ), and there wasn't any significant difference between the model group and the donepezil group in the same way (Fig. 1A). Compared with the control group, the spontaneous alternation rate of mice in the model group was significantly decreased $(p<0.01)$. However, the spontaneous alternation rate was significantly increased by donepezil $(p<0.01)$

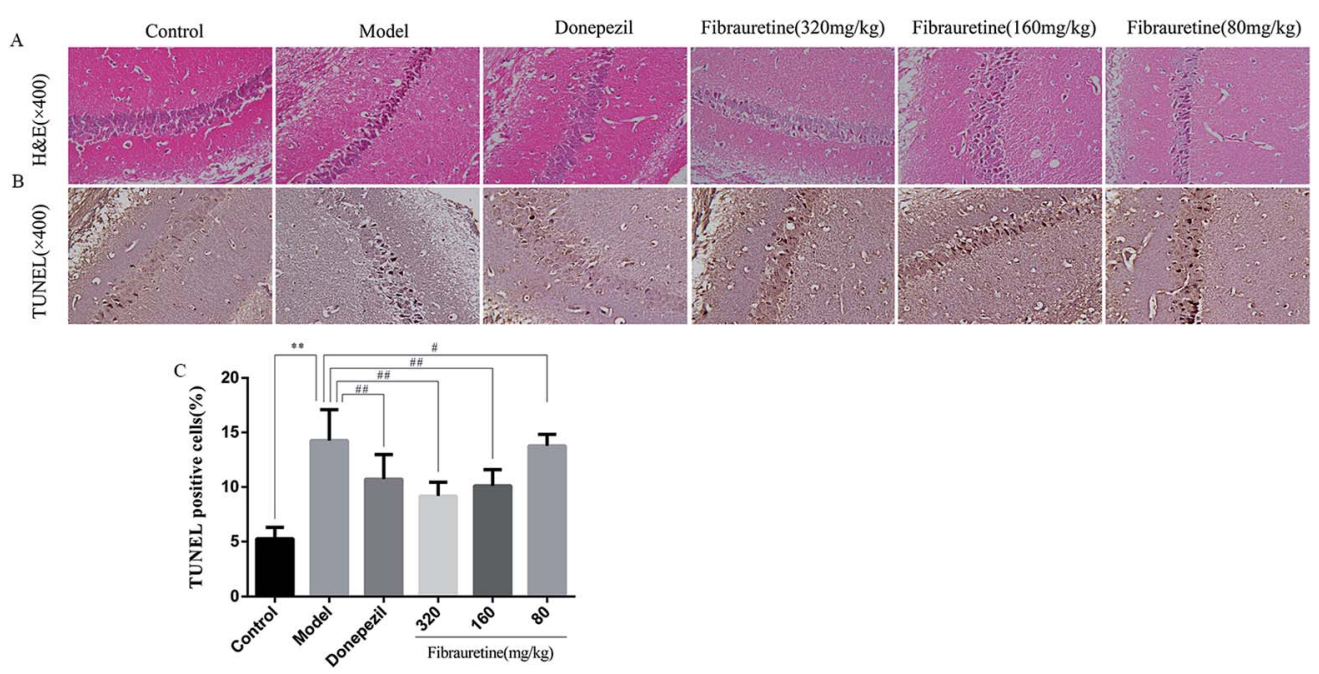

Fig. 4 Morphological changes in D-galactose/ $\mathrm{AlCl}_{3}$ induced $\mathrm{AD}$ mice. Brain tissue sections stained by H\&E ( $\left.\times 400\right)(\mathrm{A})$; brain tissue sections stained by TUNEL $(\times 400)(B)$; the presence of TUNEL positive cells measured by the image analyser $(C)$; all data are expressed as the mean \pm SD, $n=10$. ${ }^{*} p<0.05,{ }^{*} p<0.01$ vs. control group; ${ }^{\#} p<0.05,{ }^{\# \#} p<0.01$ vs. model group. 
and fibrauretine at doses of 80,160 and $320 \mathrm{mg} \mathrm{kg}^{-1}$ in a dosedependent manner $(p<0.05$ or $p<0.01)$, as shown in Fig. 1B.

In the water maze experiment, the spatial learning ability of the mice was assessed by the escape latency. The mean escape latencies are shown in Fig. 1C. The results indicate that the escape latency in the model group mice was significantly longer compared with the control group mice $(p<0.01)$. The escape latencies were significantly reduced by donepezil $(p<0.01)$, Similarly, the escape latencies were reduced by fibrauretine at doses of 80,160 and $320 \mathrm{mg} \mathrm{kg}^{-1}$ ( $p<0.05$ or $p<0.01$ ).

Spatial memory retention is assessed by the time spent in the target quadrant and the number of crossings in the target quadrant in the exploratory experiment. Compared with the control group, the time spent in the target quadrant and the number of crossings in the target quadrant in the model group mice were both significantly decreased $(p<0.01)$. In the same way, these changes in the time spent in the target quadrant and the number of passages through the target quadrant were significantly increased by donepezil $(p<0.01)$ and dosedependently increased by fibrauretine at doses of 80, 160 and $320 \mathrm{mg} \mathrm{kg}^{-1}(p<0.05$ or $p<0.01)$, as shown in Fig. 1D and E.

\subsection{Effects of fibrauretine on biochemical parameters related to $\mathrm{AD}$ in mice}

The brain levels of $\mathrm{A} \beta$, AchE, Tau, P-Tau, ChAT and Ach were determined by ELISA assay. The levels of these six biochemical parameters are closely related to $\mathrm{AD}$. They play very important roles in the process of AD. As shown in Fig. 2, compared with the control group, the brain levels of $\mathrm{A} \beta$, AchE, Tau and P-Tau in the model group were significantly increased $(p<0.01)$, and the brain levels of ChAT and Ach were significantly decreased $(p<0.01)$. A $\beta$, AchE, Tau and P-Tau levels of donepezil-administered mice were significantly decreased $(p<0.01)$. And the levels of A $\beta$, AchE, Tau and P-Tau in the fibrauretine-administered mice were significantly decreased in a dose-dependent manner $(p<0.05$ or $p<$ 0.01). On the contrary, the levels of ChAT and Ach in the brains of donepezil were significantly increased $(p<0.01)$. And ChAT, Ach levels of fibrauretine mice were significantly increased in a doseindependent manner $(p<0.05$ or $p<0.01)$. The data above indicated that fibrauretine has an obvious anti-AD effect.

\subsection{Effects of fibrauretine on the oxidative stress of the brain in D-galactose $/ \mathrm{AlCl}_{3}$-treated mice}

As previously described, oxidative stress injury participated in the mechanisms of AD. ${ }^{13}$ As indicated in Fig. 3, D-galactose $/ \mathrm{AlCl}_{3}$ treatment caused a conspicuous reduction in glutathione (GSH) level, superoxide dismutase (SOD) activity and catalase (CAT) activity, accompanied by an increase in malondialdehyde (MDA) content and nitric oxide (NO) content, compared with the control group $(p<0.01)$. However, compared with the model group, the administration of fibrauretine reduced MDA content, NO content, and recovered antioxidant capacity, as indicated by the increase in the GSH level, SOD activity and CAT activity in a dose-independent manner $(p<0.05$ or $p<0.01)$. So did the donepezil-treated group at dose of $1 \mathrm{mg} \mathrm{kg}^{-1}$. These data suggested that fibrauretine alleviated oxidative damage in the
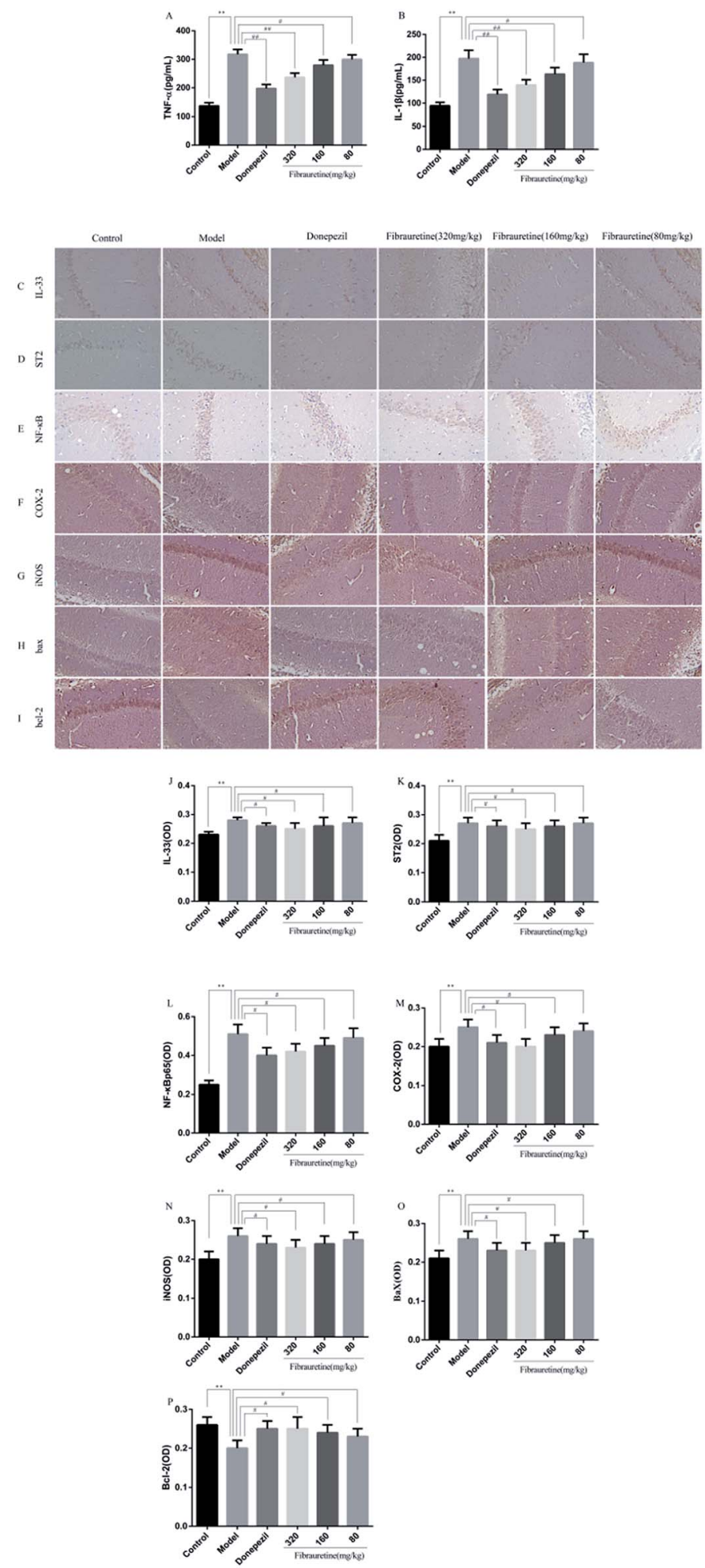

Fig. 5 Effects of fibrauretine and donepezil on the levels of TNF- $\alpha(A)$; IL-1 $\beta$ (B). Effects of fibrauretine and donepezil on the expression of: IL33 (C); ST2 (D); NF- $\mathrm{BB}(\mathrm{E})$; COX-2 (F); iNOS (G); Bax (H) and Bcl-2 (I). The column chart shows the antibodies stained area of: IL-33 (J); ST2 $(\mathrm{K})$; NF- $\kappa \mathrm{B}(\mathrm{L})$; $\mathrm{COX}-2(\mathrm{M})$; iNOS $(\mathrm{N})$; $\mathrm{Bax}(\mathrm{O})$ and $\mathrm{Bcl}-2$ (P). The protein expression was determined by immunohistochemistry in brain tissues from all groups. ${ }^{*} p<0.05,{ }^{* *} p<0.01$ vs. control group; ${ }^{\#} p<0.05,{ }^{\# \#} p$ $<0.01$ vs. model group. 
serum and brain tissues by up-regulating antioxidant enzyme activity.

\subsection{Effects of fibrauretine on histopathological changes of the brain in $\mathrm{D}$-galactose/ $\mathrm{AlCl}_{3}$-treated mice}

According to the brain tissue sections in $\mathrm{D}$-galactose $/ \mathrm{AlCl}_{3}$ induced $\mathrm{AD}$ mice, the hippocampal neuron cell growth and shape was observed by $\mathrm{H} \& \mathrm{E}$ staining (Fig. 4A). The results showed that there were fewer neurons of the hippocampus in the model group arranged heterocentrically, in which cell body, pyknotic and deeply stained nuclei shrank and the elongated axon could be found. However, these morphological changes in fibrauretine-treated group could be ameliorated. In the hippocampal region of fibrauretine $320 \mathrm{mg} \mathrm{kg}^{-1}$ and $160 \mathrm{mg} \mathrm{kg}^{-1}$ treated groups, the neurons were arranged regularly and increased, and the improvement in the structure of the hippocampus neurons was obvious. The same result as the

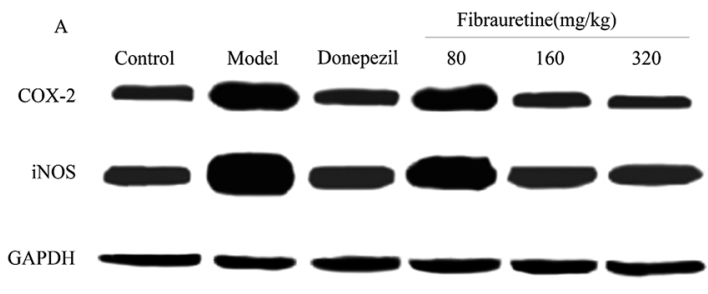

C
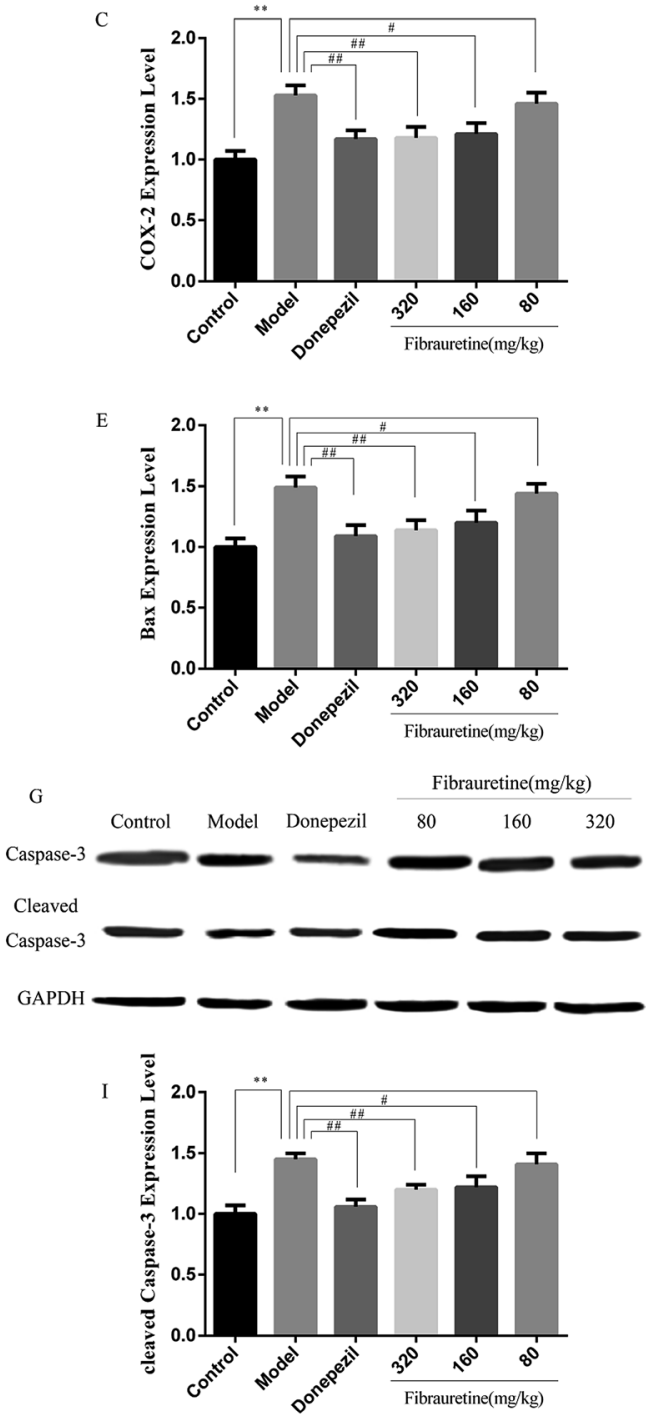

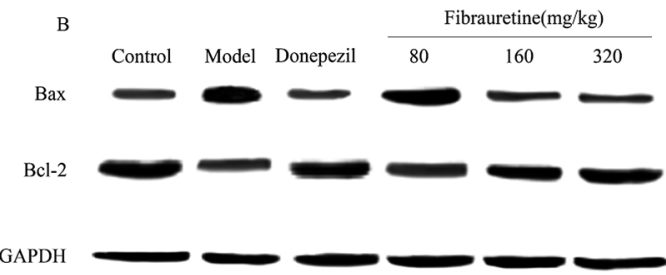

D

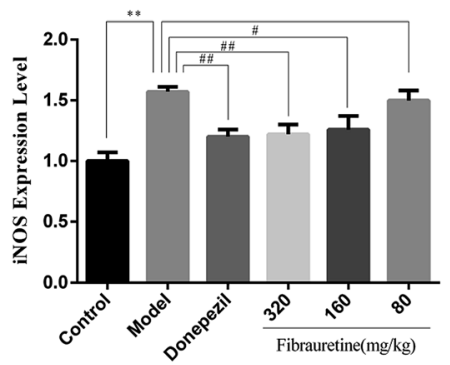

F
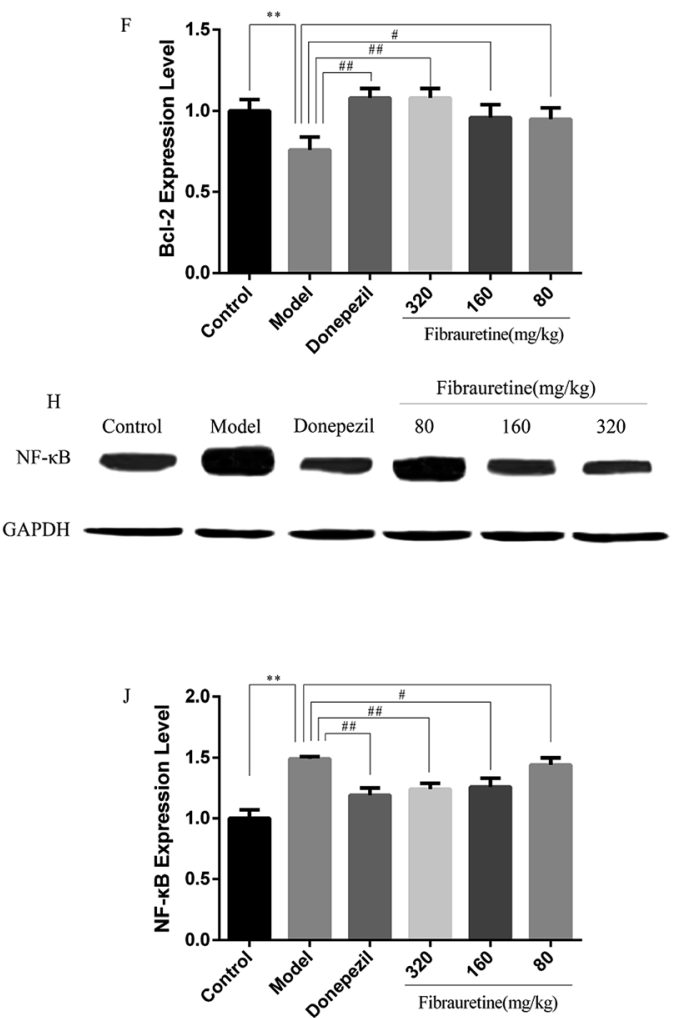

Fig. 6 Effects of fibrauretine and donepezil on the protein expression of COX-2, iNOS (A); Bax, Bcl-2 (B); caspase-3, cleaved caspase-3 (G); and NF- $\kappa B(H)$. The column chart shows antibody relative intensity of COX-2 (C); iNOS (D); Bax (E); Bcl-2(F); cleaved caspase-3 (I); NF- $\mathrm{BB}(\mathrm{J})$. The protein expression was examined by the western blotting analysis in brain tissues from all experimental groups. ${ }^{*} p<0.05, * * p<0.01$ vs. control group; ${ }^{\#} p<0.05,{ }^{\# \#} p<0.01$ vs. model group. 
fibrauretine-treated group occurred for the donepezil-treated group.

\subsection{Effects of fibrauretine on inflammation of the brain in $D^{-}$ galactose $/ \mathrm{AlCl}_{3}$-treated mice}

The previous study has confirmed that $\mathrm{AD}$ is related to the release of pro-inflammatory cytokines, including tumour necrosis factor- $\alpha$ (TNF- $\alpha)$, interleukin-1 $\beta \quad(\mathrm{IL}-1 \beta)$ and interleukin-33 (IL-33). ${ }^{37-40}$ The brain tissue levels of TNF- $\alpha$ and IL-1 $\beta$ were determined by the ELISA assay. As indicated in Fig. 5A and $\mathrm{B}$, a single $\mathrm{D}$-galactose/ $\mathrm{AlCl}_{3}$ administration resulted in obviously higher levels of TNF- $\alpha$ and IL-1 $\beta$ in the brain, compared with the control group $(p<0.01)$. However, these increases were reversed after fibrauretine administration in a dose-dependent manner $(p<0.05$ or $p<0.01)$. The levels of TNF- $\alpha$ and IL-1 $\beta$ in the donepezil-administered mice were also significantly reduced $(p<0.01)$. The levels of IL-33 and its receptor ST2 were detected by IHC analysis. As shown in Fig. 5C and D, the positive expression area of IL-33 and ST2 levels of the model group was clearly increased, compared with the control group. But fibrauretine treatment resulted in dose-dependent reduction. And the administration of donepezil also reduced the levels of IL-33 and ST2 $(p<0.05)$. Meanwhile, to further discuss the mechanisms underlying the advantageous effects of fibrauretine on D-galactose $/ \mathrm{AlCl}_{3}$-induced neuroinflammation, the levels of NF- $\kappa$ B, COX-2 and iNOS were detected in all groups (Fig. 5E-G and 6A and $\mathrm{H}$ ). Compared with the control group, the positive expression area of these protein levels of the model group was clearly improved. However, these increases were attenuated by fibrauretine at doses of 80,160 and $320 \mathrm{mg} \mathrm{kg}^{-1}$ $(p<0.05)$. So did the donepezil-treated group $(p<0.05)$.

\subsection{Effects of fibrauretine on apoptosis of the brain in $D^{-}$ galactose $/ \mathrm{AlCl}_{3}$-treated mice}

To measure the degree of apoptosis in the brains, the protein expressions of the cleaved caspase-3, anti-apoptotic factor Bcl-2 and pro-apoptotic factor Bax in all experimental groups of mice were detected. In the immunohistochemical analysis, as shown in Fig. $5 \mathrm{H}$ and I, the hippocampal pyramidal cells are stained in brown, and the positive cells are stained in yellow. Compared with the control group, the rates of positive expressions of Bax located in hippocampal pyramidal cytoplasm were observed to be clearly higher in the model group $(p<0.01)$. There is a clear reduction effect in the fibrauretine administration group $(p<$ 0.05). The donepezil-treated group showed the same therapeutic effect $(p<0.05)$. Conversely, the positive expression of Bcl-2 in the hippocampal pyramidal cytoplasm has increased in the fibrauretine groups compared to the model group $(p<0.05)$. So did the donepezil-treated group $(p<0.05)$. The results of western blotting showed that $\mathrm{D}$-galactose $/ \mathrm{AlCl}_{3}$ exposure significantly increased the expression levels of cleaved caspase3 and Bax and reduced the expression level of Bcl-2 compared with the control group $(p<0.01)$. However, similar to the results of immunohistochemistry, the levels of Bax, cleaved caspase- 3 of the fibrauretine-treated groups significantly reduced $(p<$
0.01). So did the donepezil-treated group ( $p<0.05$ ). (Fig. 6D-F) $(p<0.05)$.

The TUNEL assay can be used to detect DNA strand breaks that are associated with apoptosis. ${ }^{\mathbf{4 1}}$ To further confirm whether fibrauretine treatment could inhibit nerve cell apoptosis in $\mathrm{D}^{-}$ galactose $/ \mathrm{AlCl}_{3}$-induced $\mathrm{AD}$, the TUNEL assay was conducted (Fig. 4B). The effect on hippocampal neuron cells was represented by the colour stained, and positive staining was in brown. The results showed that fibrauretine pretreatment with $80 \mathrm{mg} \mathrm{kg}{ }^{-1}$, $160 \mathrm{mg} \mathrm{kg}^{-1}$ and $320 \mathrm{mg} \mathrm{kg}^{-1}$ decreased the number of $\mathrm{D}$-galactose/AlCl 3 -induced TUNEL-positive cells $(p<$ 0.05 or $p<0.01$ ); the same outcome occurred for the donepezil group. These results showed that fibrauretine showed suppressive effects against $\mathrm{D}$-galactose $/ \mathrm{AlCl}_{3}$-induced hippocampal neuron cell apoptosis.

\section{Discussion}

In the present study, a $\mathrm{D}$-galactose $/ \mathrm{AlCl}_{3}$-induced $\mathrm{AD}$ mice model was established to investigate the anti-AD activities of fibrauretine by intragastrical administration. Our results showed that fibrauretine significantly enhanced the spatial short-term working memory in AD mice in the Y-maze test and the spatial learning and memory in the Morris water maze. The levels of A $\beta$, P-Tau, Tau and AchE in brain tissue were evidently increased in the model group and were reversed by fibrauretine. In contrast, a significant increase in the levels of Ach and ChAT was observed in the fibrauretine-treated groups compared with the model group. The results indicated that fibrauretine exhibited ameliorative effects on $\mathrm{D}$-galactose $/ \mathrm{AlCl}_{3}$-induced $\mathrm{AD}$ in mice, in a dose-dependent manner.

A great deal of evidence has implicated oxidative stress and free radical damage in the pathogenesis of $\mathrm{AD}$. The damage found in $\mathrm{AD}$ includes advanced glycation end products, ${ }^{\mathbf{4 2}}$ nitration, ${ }^{\mathbf{4 3}}$ lipid peroxidation adduction products, ${ }^{\mathbf{4 4 , 4 5}}$ and carbonyl-modified neurofilament protein and free carbonyls. ${ }^{46,47}$ The antioxidant factors are represented by antioxidant enzymes such as superoxide dismutase (SOD), glutathione peroxidase (GPX), catalase or aldehyde dehydrogenase, and non-enzymatic antioxidant factors. The reaction of the reduction of free radicals is catalysed by the antioxidant enzymes, diminishing their power and hence oxidative cytotoxicity. ${ }^{48}$ ELISA results showed that neuronal oxidative stress was induced by D-galactose $/ \mathrm{AlCl}_{3}$ in the model group, evidenced by increased malondialdehyde (MDA) and nitric oxide (NO) levels and a decline in glutathione (GSH), catalase (CAT) and superoxide dismutase (SOD) activity. All of the above abnormality was reduced by fibrauretine in the present work. As described above, our findings illustrated which fibrauretine pretreatment recovered antioxidant ability by suppressing oxidative stress.

Numerous studies demonstrated that neuroinflammation plays a critical role in the pathogenesis of $\mathrm{AD}$, showing a clear involvement of several inflammatory pathways. ${ }^{49} \mathrm{NF}-\kappa \mathrm{B}$ is a proinflammatory transcription factor located in the cytoplasm via binding to the inhibitory $\mathrm{I} \kappa \mathrm{B}$ protein. $\mathrm{I} \kappa \mathrm{B}$ is degraded by the proteasome when it is stimulated by pathogens. Then, NF- $\kappa \mathrm{B}$ is 
freed to translocate from the cytoplasm to the nucleus where it promotes the transcription of target genes such as TNF- $\alpha$ and IL-1 $\beta$. At the same time, the up-regulation of iNOS and COX-2, via the NF- $\mathrm{B}$ pathway, is another central mechanism in inflammatory response processes. ${ }^{\mathbf{5 0}}$ Growing evidence shows that iNOS and COX-2 are clearly highly expressed at sites of inflammation. Moreover, iNOS and COX-2 have synergistic effects to accelerate the inflammatory response. ${ }^{51} \mathrm{IL}-33$ serves as a proinflammatory cytokine and an intra-cellular nuclear factor regulating transcription. IL-33 may be a specific proinflammatory cytokine in the CNS. ${ }^{52}$ IL-33 receptors containing a trans-membrane portion called ST2 are expressed in microglia and astrocytes. The glial cells respond by proliferating and releasing TNF- $\alpha$, IL- $1 \beta$, and NO. ${ }^{40}$ IL- $1 \beta$ and TNF- $\alpha$ are released by IL-33 from inflammatory cells. ${ }^{39}$ Both IL-1 $\beta$ and TNF- $\alpha$ were increased in the brains of AD patients compared to control subjects. ${ }^{38}$ Fibrauretine has traditionally been used as the anti-inflammatory agent. However, its anti-inflammatory mechanism is not clear. In this study, to discuss the potential molecular mechanisms and the anti-AD effects of fibrauretine against $\mathrm{D}$-galactose $/ \mathrm{AlCl}_{3}$-induced inflammation in depth, we detected the expression levels of NF- $\kappa \mathrm{B}, \mathrm{COX}-2$, iNOS, IL-33 and ST2. Western blotting and immunohistochemistry analysis of the results showed that fibrauretine pretreatment significantly down-regulated the increase in expression levels of NF- $\kappa \mathrm{B}, \mathrm{COX}-$ 2 , iNOS, as well as IL-33 and ST2 after D-galactose/ $/ \mathrm{AlCl}_{3}$ exposure. Moreover, ELISA results revealed that D-galactose $/ \mathrm{AlCl}_{3}$ administration increased the levels in TNF- $\alpha$ and IL-1 $\beta$. Nevertheless, the increase in inflammatory cytokine levels against $\mathrm{D}^{-}$ galactose $/ \mathrm{AlCl}_{3}$-induced mice was dramatically suppressed by fibrauretine. The possible molecular mechanisms are involved in the suppression of such cytokines by fibrauretine. In short, the results suggested that fibrauretine could act as an antiinflammatory agent against D-galactose $/ \mathrm{AlCl}_{3}$-induced $\mathrm{AD}$.

There is growing evidence that $\mathrm{AD}$ is related to apoptosis. The accumulation of $\mathrm{A} \beta$ can induce neuronal apoptosis, which plays a vital role in $\mathrm{AD}$ pathogenesis. ${ }^{53}$ The conditions inducing apoptosis that include reactive oxygen species (ROS), nitric oxide (NO), glucocorticoids and Bax overexpression are known as major factors causing the release of cytochrome $c$ (Cyt $c$ ). ${ }^{54,55}$ The Bcl-2 family of proteins strictly regulates Cyt $c$ release. ${ }^{56}$ The family is composed of anti-apoptosis protein such as Bcl-2 and pro-apoptotic protein such as Bax. The balance between antiand pro-apoptotic proteins determines the activation of intrinsic apoptotic signals involving mitochondria. ${ }^{57}$ When upstream caspases such as caspase- 9 are activated, downstream effector caspase cleavage such as caspase- 3 will be triggered, and they can cleave cytoskeletal and nuclear proteins to induce apoptosis. ${ }^{58}$ For evaluated levels of apoptosis in brain tissues following D-galactose/ $\mathrm{AlCl}_{3}$ administration, the effects of fibrauretine were assessed by cleaved caspase-3, pro-apoptotic factor Bax and anti-apoptotic factor Bcl-2 in every pretreatment group. The findings from protein detection analyses of brains markedly showed that the expression levels of Bax, caspase-3, and cleaved caspase- 3 were suppressed, while the expression level of Bcl-2 was relatively activated. Additionally, the results of TUNEL staining displayed that the apoptosis rate in brain tissues was clearly reduced by fibrauretine when compared with the model group. In summary, the above results demonstrated that fibrauretine inhibited the apoptosis of brain tissues in D-galactose $/ \mathrm{AlCl}_{3}$-induced $\mathrm{AD}$ mice.

In summary, $\mathrm{AD}$ is a complex disease involving many genetic and environmental factors. Oxidative stress has been shown to induce apoptosis by inducing cytochrome $c$ release and activating caspase-9 and caspase- $3,{ }^{59}$ and overproduction of free radicals would be followed by an inflammatory response. ${ }^{60}$ Among various potential causes, inflammation has been suggested to be a predisposing factor in the development of neurodegenerative diseases including AD.

Nuclear factor kappa B (NF- $\kappa \mathrm{B})$ is a key inflammatory mediator that regulates the expression of various genes that involved in apoptosis and inflammation. ${ }^{61} \mathrm{NF}-\kappa \mathrm{B}$ is usually kept inactive in the cytoplasm through association with an endogenous inhibitor protein of the I $\kappa \mathrm{B}$ family. ${ }^{62}$ Activated NF- $\kappa \mathrm{B}$ could increase the expression of other inflammatory mediators such as COX-2, iNOS, IL-1 $\beta$ and TNF- $\alpha$, which might be triggered memory impairment. ${ }^{21}$ Interestingly, ROS accumulation in response to TNF- $\alpha$ is regulated in an NF- $\kappa \mathrm{B}$-dependent manner. ${ }^{63}$ Previous study has found that inhibition of NF- $\kappa \mathrm{B}$ inhibits apoptosis during the resolution of inflammation in vivo and expression of genes involved in apoptosis, including the pro-apoptotic Bcl-2 homolog Bax, was modulated by NF- $\kappa \mathrm{B}$ inhibitors. ${ }^{64}$ Thus it can be seen that NF- $\kappa$ B plays a very important role and may be a key factor in the onset of $\mathrm{AD}$. The immunohistochemistry and western blotting results from our study demonstrated that fibrauretine can inhibit the activation of NF- $\kappa$ B. Several studies have also revealed that fibrauretine can restrain the activation of $\mathrm{NF}-\kappa \mathrm{B}$ in other cell models or animal models. ${ }^{65-69}$

So fibrauretine from Fibraurea recisa Pierre ameliorate Dgalactose $/ \mathrm{AlCl}_{3}$-mediated Alzheimer's disease probably by suppressing the NF- $\kappa \mathrm{B}$ pathways.

\section{Conclusion}

In addition to being clinically used as an anti-inflammatory drug, fibrauretine has been found to have a significant anti$\mathrm{AD}$ effect, the mechanism is inextricably linked to antiinflammatory, anti-oxidation and anti-apoptosis.

\section{Conflicts of interest}

There are no conflicts of interest to declare.

\section{Acknowledgements}

The authors are grateful to the National Natural Science Foundation of China (grant no. 31502109) and Jilin Province Science and Technology Development Program (grant No. 20180414072GH and No. 20160209006YY). We declare that there are no financial or other contractual agreements that might cause conflicts of interest or be perceived as causing conflicts of interest. 


\section{References}

1 D. Farfara, V. Lifshitz and D. Frenkel, Neuroprotective and neurotoxic properties of glial cells in the pathogenesis of Alzheimer's disease, J. Cell. Mol. Med., 2010, 12(3), 762-780.

2 D. Paris, et al., Reduction of beta-amyloid pathology by celastrol in a transgenic mouse model of Alzheimer's disease, J. Neuroinflammation, 2010, 7(1), 1-15.

3 K. Blennow, M. J. D. Leon and H. Zetterberg, Alzheimer's disease, Lancet, 2006, 368(9533), 387-403.

4 A. K. Fu, et al., IL-33 ameliorates Alzheimer's disease-like pathology and cognitive decline, Proc. Natl. Acad. Sci. U. S. A., 2016, 113(19), E2705-E2713.

5 R. Thangavel, et al., Expression of glia maturation factor in neuropathological lesions of Alzheimer's disease, Neuropathol. Appl. Neurobiol., 2012, 38(6), 572-581.

$6 \mathrm{X}$. Fei, H. Sun and Y. N. Sun, Aluminum and Alzheimer's Disease, Med. Recapitulate, 2009, 7(6), 525-532.

7 L. Liaquat, et al., Development of $\mathrm{AD}$ like symptoms following co-administration of $\mathrm{AlCl}_{3}$ and D-gal in rats: a neurochemical, biochemical and behavioural study, Pak. J. Pharm. Sci., 2017, 30(suppl. 2), 647-653.

$8 \mathrm{Y}$. Wei, et al., Protective effects of kinetin against aluminum chloride and D-galactose induced cognitive impairment and oxidative damage in mouse, Brain Res. Bull., 2017, 134, 262272.

9 E. E. Tuppo and H. R. Arias, The role of inflammation in Alzheimer's disease, Int. J. Biochem. Cell Biol., 2005, 37(2), 289-305.

10 W. B. Cherry, et al., A novel IL-1 family cytokine, IL-33, potently activates human eosinophils, J. Allergy Clin. Immunol., 2008, 121(6), 1484-1490.

11 Z. Xiong, et al., Alzheimer's disease: evidence for the expression of interleukin-33 and its receptor ST2 in the brain, J. Alzheimer's Dis., 2013, 40(2), 297-308.

12 Z. N. Ma, et al., Nephroprotective effects of saponins from leaves of Panax quinquefolius against cisplatin-induced acute kidney injury, Int. J. Mol. Sci., 2017, 18(7), 1407.

13 G. Perry, A. D. Cash and M. A. Smith, Review Article Alzheimer Disease and Oxidative Stress, J. Biomed. Biotechnol., 2002, 2(3), 120-123.

14 B. D. Sahu, et al., Ameliorative Effect of Fisetin on CisplatinInduced Nephrotoxicity in Rats via Modulation of NF- $\kappa \mathrm{B}$ Activation and Antioxidant Defence, PLoS One, 2014, 9(9), e105070.

15 P. N. Pompl, et al., Caspase gene expression in the brain as a function of the clinical progression of Alzheimer disease, Arch. Neurol., 2003, 60(3), 369-376.

16 R. E. Tanzi, R. D. Moir and S. L. Wagner, Clearance of Alzheimer's Abeta peptide: the many roads to perdition, Neuron, 2004, 43(5), 605-608.

17 Y. Wang, et al., Ginsenoside Rb1 inhibit apoptosis in rat model of Alzheimer's disease induced by A $\beta 1-40, A m . J$. Transl. Res., 2018, 10(3), 796-805.
18 M. D'Amelio, M. Sheng, F. Cecconi, et al., Caspase-3 in the central nervous system: beyond apoptosis, Trends Neurosci., 2012, 35(11), 700-709.

19 M. Huang, et al., Berberine improves cognitive impairment by promoting autophagic clearance and inhibiting production of $\beta$-amyloid in APP/tau/PS1 mouse model of Alzheimer's disease, Exp. Gerontol., 2017, 91, 25-33.

$20 \mathrm{Y}$. Kwon, Luteolin as a potential preventive and therapeutic candidate for Alzheimer's disease, Exp. Gerontol., 2017, 95, 39-43.

21 Z. Qu, et al., Protective effect of tetrahydropalmatine against D-galactose induced memory impairment in rat, Physiol. Behav., 2016, 154(11), 114-125.

$22 \mathrm{~J}$. Wu, et al., Palmatine hydrochloride mediated photodynamic inactivation of breast cancer MCF-7 cells: effectiveness and mechanism of action, Photodiagn. Photodyn. Ther., 2016, 15, 133-138.

$23 \mathrm{~J}$. Wu, et al., Photodynamic action of palmatine hydrochloride on colon adenocarcinoma HT-29 cells, Photodiagn. Photodyn. Ther., 2016, 15, 53-58.

$24 \mathrm{X}$. Zhou, et al., Chondroprotective effects of palmatine on osteoarthritis in vivo and in vitro: a possible mechanism of inhibiting the Wnt/ $\beta$-catenin and Hedgehog signaling pathways, Int. Immunopharmacol., 2016, 34, 129-138.

25 F. Jia, et al., Identification of palmatine as an inhibitor of West Nile virus, Arch. Virol., 2010, 155(8), 1325-1329.

26 Y. Yang, et al., Chemical profiling and quantification of Chinese medicinal formula Huang-Lian-Jie-Du decoction, a systematic quality control strategy using ultra high performance liquid chromatography combined with hybrid quadrupole-orbitrap and triple quadrupole mass spe, $J$. Chromatogr. A, 2013, 1321(24), 88-99.

$27 \mathrm{H}$. Zou, et al., Induced Cortical Neurogenesis after Focal Cerebral Ischemia - Three Active Components from Huang-Lian-Jie-Du Decoction, J. Ethnopharmacol., 2016, 178, 115-124.

28 D. Dhingra and A. Bhankher, Behavioral and biochemical evidences for antidepressant-like activity of palmatine in mice subjected to chronic unpredictable mild stress, Pharmacol. Rep., 2014, 66(1), 1-9.

$29 \mathrm{H}$. Wu, et al., The antihypercholesterolemic effect of jatrorrhizine isolated from Rhizoma Coptidis, Phytomedicine, 2014, 21(11), 1373-1381.

30 Z. Xing, et al., Synthesis of Palmatine Derivatives and Their Inhibition of Acetylcholinesterase Activity, Chin. J. Anal. Chem., 2018, 5(46), p684-689.

$31 \mathrm{~S}$. Zhu, et al., Therapeutic effects of quetiapine on memory deficit and brain $\beta$-amyloid plaque pathology in a transgenic mouse model of Alzheimer's disease, Curr. Alzheimer Res., 2013, 10(3), 270-278.

32 L. W. Means and K. J. P. Kennard, Working memory and the aged rat: deficient two-choice win-stay water-escape acquisition and retention, Physiol. Behav., 1991, 49(2), 301307.

$33 \mathrm{~S}$. Zhu, et al., The role of neuroinflammation and amyloid in cognitive impairment in an APP/PS1 transgenic mouse 
model of Alzheimer's disease, CNS Neurosci. Ther., 2017, 23(4), 310-320.

$34 \mathrm{X}$. Bian, et al., Chiisanoside, a triterpenoid saponin, exhibits anti-tumor activity by promoting apoptosis and inhibiting angiogenesis, RSC Adv., 2017, 7(66), 41640-41650.

35 Z. Sun, et al., Development and validation of a sensitive UHPLC-MS/MS method for quantitation of prucalopride in rat plasma and its application to pharmacokinetics study, J. Chromatogr. B: Anal. Technol. Biomed. Life Sci., 2016, 1033-1034, 328-333.

$36 \mathrm{~W}$. Li, et al., Hypoglycemic effect of protopanaxadiol-type ginsenosides and compound $\mathrm{K}$ on type 2 diabetes mice induced by high-fat diet combining with streptozotocin via suppression of hepatic gluconeogenesis, Fitoterapia, 2012, 83(1), 192-198.

37 A. Kobori, et al., Interleukin-33 expression is specifically enhanced in inflamed mucosa of ulcerative colitis, $J$. Gastroenterol., 2010, 45(10), 999-1007.

38 D. A. Llano, et al., Cerebrospinal fluid cytokine dynamics differ between Alzheimer disease patients and elderly controls, Alzheimer Dis. Assoc. Disord., 2012, 26(4), 322-328.

39 D. Moulin, et al., Interleukin (IL)-33 induces the release of pro-inflammatory mediators by mast cells, Cytokine, 2007, 40(3), 216-225.

40 S. Yasuoka, et al., Production and functions of IL-33 in the central nervous system, Brain Res., 2011, 1385(6), 8-17.

41 A. M. Mesa, et al., Stallion semen incubated with hydrogen peroxide decreased DNA fragmentation as measured by the TUNEL assay, J. Equine Vet. Sci., 2017, 49, 81-86.

42 M. A. Smith, et al., Advanced Maillard Reaction End Products, Free Radicals, and Protein Oxidation in Alzheimer's Diseasea, Ann. N. Y. Acad. Sci., 1994, 447-454.

43 M. A. Smith, et al., Widespread peroxynitrite-mediated damage in Alzheimer's disease, J. Neurosci., 1997, 17(8), 2653-2657.

44 T. J. Montine, et al., E-4-Hydroxy-2-nonenal is cytotoxic and cross-links cytoskeletal proteins in P19 neuroglial cultures, Am. J. Pathol., 1996, 148(1), 89-93.

45 L. M. Savre, et al., 4-Hydroxynonenal-derived lipid peroxidation end products are increased is Alzheimer disease, J. Neuropathol. Exp. Neurol., 1997, 56(5), 13.

46 C. D. Smith, et al., Excess Brain Protein Oxidation and Enzyme Dysfunction in Normal Aging and in Alzheimer Disease, Proc. Natl. Acad. Sci. U. S. A., 1991, 88(23), 1054010543.

47 M. A. Smith, et al., Carbonyl-related posttranslational modification of neurofilament protein in the neurofibrillary pathology of Alzheimer's disease, $J$. Neurochem., 2010, 64(6), 2660-2666.

48 W. R. Markesbery, Oxidative stress hypothesis in Alzheimer's disease, Free Radical Biol. Med., 1997, 23(1), 134-147.

49 S. Ravichandran, A. Michelucci and A. del Sol, Integrative Computational Network Analysis Reveals Site-Specific Mediators of Inflammation in Alzheimer's Disease, Front. Physiol., 2018, 9(154), DOI: 10.3389/fphys.2018.00154.

$50 \mathrm{~F}$. Aktan, iNOS-mediated nitric oxide production and its regulation, Life Sci., 2004, 75(6), 639-653.
51 S. H. Itzkowitz, Molecular Biology of Dysplasia and Cancer in Inflammatory Bowel Disease, Gastroenterol. Clin. North Am., 2006, 35(3), 553-571.

52 C. A. Hudson, et al., Induction of IL-33 expression and activity in central nervous system glia, J. Leukocyte Biol., 2008, 84(3), 631-643.

53 Z. D. Zhou, et al., The roles of amyloid precursor protein (APP) in neurogenesis, implications to pathogenesis and therapy of Alzheimer disease (AD), Cell Adhes. Migr., 2011, 5(4), 280-292.

54 D. R. Green and J. C. Reed, Mitochondria and apoptosis, Science, 1998, 281(5381), 1309-1312.

55 K. Guido and B. Klas, Mitochondrial Cell Death Control in Familial Parkinson Disease, PLoS Biol., 2007, 5(7), e206.

56 J. M. Adams and S. Cory, The Bcl-2 protein family: arbiters of cell survival, Science, 1998, 281(5381), 1322-1326.

57 R. S. Woo, et al., Expression of ErbB4 in the apoptotic neurons of Alzheimer's disease brain, Anat. Cell. Biol., 2010, 43(4), 332-339.

58 A. Ashkenazi and V. M. Dixit, Death Receptors: Signaling and Modulation, Science, 1998, 281(5381), 1305-1308.

59 S. Figueroa, et al., Mitochondrial involvement in nitric oxideinduced cellular death in cortical neurons in culture, $J$. Neurosci. Res., 2006, 83(3), 441-449.

60 M. X. Yan, et al., Long-term high-fat diet induces pancreatic injuries via pancreatic microcirculatory disturbances and oxidative stress in rats with hyperlipidemia, Biochem. Biophys. Res. Commun., 2006, 347(1), 192-199.

61 R. O. EscÃ rcega, et al., The transcription factor nuclear factor-kappa B and cancer, Clin. Oncol., 2007, 19(2), 154-161.

$62 \mathrm{M}$. Karin and Y. Benneriah, Phosphorylation meets ubiquitination: the control of NF-[kappa]B activity, Annu. Rev. Immunol., 2000, 18(1), 621-663.

63 S. Sakon, et al., NF-kappaB inhibits TNF-induced accumulation of ROS that mediate prolonged MAPK activation and necrotic cell death, EMBO J., 2003, 22(15), 3898-3909.

64 C. Yin, et al., Bax suppresses tumorigenesis and stimulates apoptosis in vivo, Nature, 1997, 385(6617), 637.

65 H. G. Hambright, et al., Palmatine inhibits growth and invasion in prostate cancer cell: potential role for rpS6/ NFкB/FLIP, Mol. Carcinog., 2015, 54(10), 1227-1234.

$66 \mathrm{~L}$. Jiwon, et al., Palmatine attenuates osteoclast differentiation and function through inhibition of receptor activator of nuclear factor- $\mathrm{B}$ ligand expression in osteoblast cells, Biol. Pharm. Bull., 2010, 33(10), 1733-1739.

67 Y. M. Kim, et al., Palmatine from Coptidis rhizoma reduces ischemia-reperfusion-mediated acute myocardial injury in the rat, Food Chem. Toxicol., 2009, 47(8), 2097-2102.

68 L. Woocheol, et al., Palmatine attenuates D-galactosamine/ lipopolysaccharide-induced fulminant hepatic failure in mice, Food Chem. Toxicol., 2010, 48(1), 222-228.

69 B. Yan, et al., Palmatine inhibits TRIF-dependent NF- $\kappa$ B pathway against inflammation induced by LPS in goat endometrial epithelial cells, Int. Immunopharmacol., 2017, 45, 194-200. 